\title{
SHORT REPORT: PROXIMITY TO MOSQUITO BREEDING SITES AS A RISK FACTOR FOR CLINICAL MALARIA EPISODES IN AN URBAN COHORT OF UGANDAN CHILDREN
}

\author{
SARAH G. STAEDKE, E. WILLIS NOTTINGHAM, JONATHAN COX, MOSES R. KAMYA, PHILIP J. ROSENTHAL, AND \\ GRANT DORSEY \\ Department of Medicine, San Francisco General Hospital, University of California, San Francisco, California; Makerere University \\ Medical School, Kampala, Uganda; Department of Infectious and Tropical Diseases, London School of Hygiene and Tropical \\ Medicine, London, United Kingdom
}

\begin{abstract}
The impact of geography on incidence of clinical episodes of malaria was investigated in a cohort of children enrolled in a longitudinal clinical trial of antimalarial therapy in Kampala, Uganda. Participant households and the boundaries of local swamps and streams were mapped and incidence of clinical malaria episodes was measured prospectively using passive surveillance during one year of follow-up. Of 316 cohort participants, 305 from 219 households were followed for at least six weeks and were included in the analysis. Incidence of clinical malaria was highly variable, with no episodes occurring in 131 participants, and 367 new episodes of malaria diagnosed in the remaining 174 children. A gradient in incidence of clinical episodes of malaria was observed with distance of residence from a swamp ( 0.41 episodes per person year for residence $>100$ meters from a swamp increasing to 2.22 episodes per person year for residence within a swamp), or a stream ( 0.61 episodes per person year for residence $\geq 500$ meters from a stream versus 1.76 episodes per person year for residence $<500$ meters from a stream). Multivariate analysis showed that distances of residence from a swamp or from a stream were independent predictors of malaria incidence, controlling for age, use of preventative measures, and primary source of water. Distance from a swamp was the strongest predictor, with an incidence rate ratio of $4.3(95 \%$ confidence interval $=2.6-6.9, P<0.001)$ between residence within a swamp and $>100$ meters from a swamp. In this urban setting, incidence of clinical episodes of malaria was strongly associated with proximity of residence to potential mosquito breeding sites.
\end{abstract}

Control of malaria in Africa presents a significant challenge. ${ }^{1}$ Targeting existing methods for malaria control to populations at greatest risk could increase the effectiveness of interventions. ${ }^{2}$ Urbanization is occurring rapidly in subSaharan Africa and may have a significant impact on the epidemiology of malaria. ${ }^{3}$ Although malaria transmission is lower in urban than in rural areas of Africa, transmission and parasite prevalence may be heterogenous within densely populated areas, clustering near mosquito breeding sites. ${ }^{3-5}$ Risk of malaria, as measured by parasite prevalence, estimated annual malaria incidence, and risk of clinical illness, has been shown to increase with mosquito exposure $;^{4-6}$ however, some data suggest that parasite prevalence ${ }^{7}$ and clinical illness ${ }^{8}$ are less common in more exposed children, possibly due to increased acquired immunity. Global positioning system (GPS) and geographic information system (GIS) technology coupled with clinical data can be used to identify geographic areas at greatest malaria risk. ${ }^{2}$ In this study, GPS and GIS were used to map the location of households in a cohort of Ugandan children followed prospectively for one year, allowing us to examine the relationship between location of residence and incidence of clinical episodes of malaria in an urban area.

This study was part of a longitudinal randomized trial that has been described elsewhere. ${ }^{9}$ Briefly, community-based, convenience sampling was used to identify interested parents or guardians of healthy children between the ages of 6 and 59 months residing in the Kawempe division of Kampala, Uganda. Kawempe has an estimated population of 153,900 and covers an area of approximately 3,245 hectares (Kampala City Council, 1998, unpublished data). Although recent entomologic data are lacking, malaria is considered meso-endemic in Kampala (parasite rate $=25 \%$, spleen rate $=25 \%$ in children 2-9 years of age) with peaks associated with the two rainy seasons (Ugandan Ministry of Health, unpublished data). Primary caregivers of participants were interviewed after enrollment and information was collected on malariarelated knowledge, attitudes, and practices, household demographics, measures of socioeconomic status, and household and environmental characteristics. ${ }^{10}$ The study was reviewed and approved by the Uganda National Council of Science and Technology, and the Institutional Review Boards of the University of California, San Francisco and Makerere University, Kampala.

At the time of enrollment, participants were randomized to receive one of three treatments (sulfadoxine-pyrimethamine [SP], SP plus amodiaquine, or SP plus artesunate) for each episode of uncomplicated malaria diagnosed during the oneyear follow-up period. ${ }^{9}$ Participants were instructed to seek all medical care at the clinic, and each time they presented with a temperature $\geq 38.0^{\circ} \mathrm{C}$ tympanic or history of fever during the previous 48 hours a thick blood smear was prepared and evaluated for malaria parasites. Criteria used to diagnose malaria are described elsewhere. ${ }^{9}$ For all recurrent episodes of malaria, genotyping was done to distinguish recrudescence (treatment failure) from new infections as previously described. ${ }^{9}$ In this study, a new episode was defined as a first episode of malaria or a subsequent episode fulfilling our criteria for new infections based on genotyping results. Time at risk was defined as the longest duration lived at any one household within Kawempe. A participant's time at risk was corrected if they moved residence within or out of Kawempe, and for first- and second-line antimalarial treatments received. The 14 days following each treatment of malaria were not considered time at risk because new infections were unlikely during this period.

Participant household locations were mapped using a handheld GPS receiver (eTrex Legend; Garmin, Olathe, KS), with an accuracy goal of $<15 \mathrm{~m}$ (Figure 1). If participants lived in the same house, or in immediately adjacent houses, one read- 


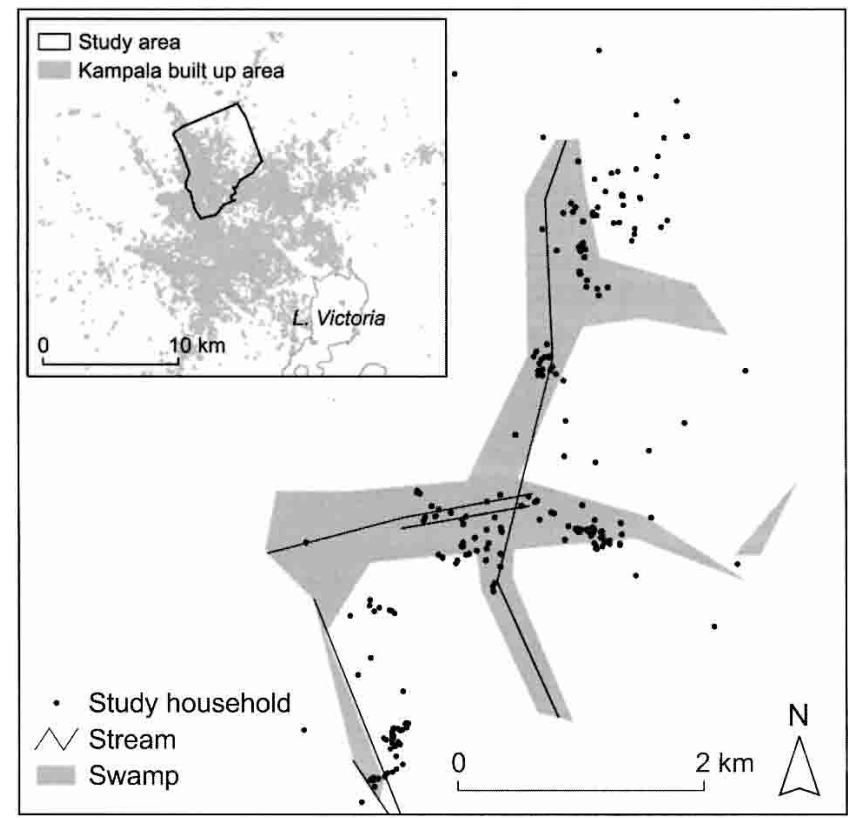

FIGURE 1. Map of Kampala, Uganda showing the location of the Kawempe Division (study area), participant households, and local swamps and streams.

ing was taken. Similar readings were taken for the boundaries of the division and local swamps and streams. A swamp was defined as a low-lying area with frequent standing water, particularly in times of steady rainfall. Distances of households to swamps and streams within Kawempe were calculated using ARC/INFO GIS software (Version 7; Environmental Systems Research Institute, Redlands, CA).

Malaria incidence density was defined as the number of new episodes of malaria per time at risk. Independent predictors of malaria incidence density were identified using a multivariate negative binomial regression model, controlling for clustering of clinical episodes of malaria for participants living in the same household and other risk factors previously identified including age, primary source of water, and use of malaria preventative measures. ${ }^{10}$ Statistical analysis was performed using STATA statistical software (Stata Corporation, College Station, TX).

Of the 316 subjects enrolled in the primary study, 305 from 219 households completed at least six weeks of follow-up, and were included in the analysis. The follow-up period covered approximately the same calendar year for all subjects. The cumulative period of observation in the primary cohort covered $93 \%$ of potential follow-up time, and 282 subjects $(89 \%)$ completed the full one-year of follow-up. Parasite prevalence at the time of enrollment was $17 \%$, supporting the classification of Kampala as a mesoendemic area. ${ }^{11}$ Incidence of clinical episodes of malaria varied greatly, with 367 new malaria episodes diagnosed in $174(57 \%)$ children (incidence range = 1-14 episodes per person year). Malaria was not diagnosed in the remaining $131(43 \%)$ children. Univariate analyses showed that distance of residence from a swamp was associated with a gradient in incidence of clinical episodes of malaria, increasing from 0.41 (residence $>100$ meters from a swamp) to 2.22 (residence within a swamp) (Table 1). Residence near a stream also impacted on incidence of clinical malaria episodes, with a decrease in incidence density ob-
TABLE 1

Participant household location and incidence density

\begin{tabular}{|c|c|c|c|c|}
\hline Geographic variable & $\begin{array}{l}\text { Number of } \\
\text { children }\end{array}$ & $\begin{array}{l}\text { Number of new } \\
\text { episodes of } \\
\text { symptomatic } \\
\text { malaria* }\end{array}$ & $\begin{array}{l}\text { Time at } \\
\text { risk (days) }\end{array}$ & $\begin{array}{l}\text { Incidence density } \\
\text { (per person year) }\end{array}$ \\
\hline \multicolumn{5}{|c|}{$\begin{array}{l}\text { Distance from } \\
\text { swamp (meters) }\end{array}$} \\
\hline$>100$ & 88 & 32 & 28,518 & 0.41 \\
\hline $1-100$ & 44 & 39 & 13,919 & 1.02 \\
\hline 0 & 173 & 296 & 48,738 & 2.22 \\
\hline \multicolumn{5}{|c|}{$\begin{array}{l}\text { Distance from } \\
\text { stream (meters) }\end{array}$} \\
\hline$\geq 500$ & 72 & 38 & 22,814 & 0.61 \\
\hline$<500$ & 233 & 329 & 68,361 & 1.76 \\
\hline
\end{tabular}

served with residence $\geq 500$ meters compared with residence $<500$ meters from a stream (Table 1). Multivariate analysis, controlling for other previously identified risk factors, showed that distance of residence from a swamp and from a stream were independent predictors of incidence of clinical episodes of malaria; distance from a swamp was the stronger predictor (Table 2).

In this study, we prospectively measured the association between proximity of residence to vector breeding sites and episodes of clinical malaria over an extended risk period, controlling for other potential risk factors. In this urban cohort, residence near potential mosquito breeding sites was associated with an increased risk of clinical malaria episodes. Distance of a household from a swamp appeared to be a more important factor than distance from a stream. Significant variation in the incidence of clinical episodes of malaria was observed over small distances. Our results support previous studies conducted in urban and peri-urban areas of Africa suggesting that malaria risk is heterogeneous over small geographic areas and is highest near mosquito breeding sites. ${ }^{4-6}$ In a rural area of The Gambia, children who lived near mosquito breeding sites had a higher parasite prevalence, but lower likelihood of clinical illness upon infection, compared with children who lived farther from breeding sites; this is likely due to greater antimalarial immunity. ${ }^{8}$ At the lower levels of transmission typically seen in urban environments, the relative importance of immunity in affording protection against clinical illness may be less than in rural areas. ${ }^{3}$ Our data and other studies suggest that reducing exposure in urban settings significantly reduces the risk of clinical illness. ${ }^{5,6}$

With the spread of antimalarial drug resistance, control of malaria in Africa can no longer rely solely on chemotherapy and effective case management. An integrated approach, in-

TABLE 2

Multivariate analysis of associations between geography and incidence of clinical episodes of malaria*

\begin{tabular}{lrrrc}
\hline Variable & Comparison groups & IRR & $95 \%$ CI & $P$ \\
\hline $\begin{array}{l}\text { Distance from swamp } \\
\text { (meters) }\end{array}$ & $1-100$ vs. $>100$ & 2.4 & $1.2-4.7$ & 0.01 \\
$\begin{array}{l}\text { Distance from stream } \\
\text { (meters) }\end{array}$ & 0 vs. $>100$ & 4.3 & $2.6-6.9$ & $<0.001$ \\
\hline
\end{tabular}

* IRR $=$ incidence rate ratio controlling for age, use of preventative measures (none vs. use of bed nets or chemoprophylaxis), and primary source of water (open spring or well vs. closed tap), and clustering of clinical episodes of malaria for participants living in the same household. $\mathrm{CI}=$ confidence interval. 
cluding vector control strategies, will be necessary to reduce malaria-associated morbidity and mortality. ${ }^{12}$ Urban areas, with dense population and easily located mosquito breeding sites, may be prime targets for antimalarial control activities. ${ }^{3}$ Identifying areas at highest malaria risk may allow for more efficient targeting of vector control methods, including use of insecticide treated nets, house spraying, larvicide application, and elimination of breeding sites.

Received February 15, 2003. Accepted for publication May 27, 2003.

Acknowledgments: We thank the clinical study team of Marx Dongo, B. M. Karakire, Sam Nsobya, Moses Kiggundu, Christopher Bongole, Regina Nakafero, Denise Njama, Bridget K. Nzarubara, Pauline Byakika, and Sarah Kibirango; the community leaders from the Kawempe Division of Kampala; and the study participants and their parents/guardians.

Financial support: This study was supported by the Fogarty International Center/National Institutes of Health (grants TW00007, TW01506, and AI-43301), the UNDP/World Bank/World Health Organization Special Program for Research and Training in Tropical Diseases (TDR), the David E. Rogers Fellowship (New York Academy of Medicine), and the University of California, San Francisco, Rainer Fund.

Authors' addresses: Sarah G. Staedke, E. Willis Nottingham, Philip J. Rosenthal, Grant Dorsey, Department of Medicine, University of California, San Francisco, San Francisco, CA 94143. Jonathan Cox, Department of Infectious and Tropical Diseases, London School of Hygiene and Tropical Medicine, Keppel Street, London WC1E 7HT, United Kingdom. Moses R. Kamya, Makerere University Medical School, Kampala, Uganda.

Reprint requests: Philip J. Rosenthal, Department of Medicine, University of California, San Francisco, Box 0811, San Francisco, CA 94143, Telephone: 415-206-8845, Fax: 415-648-8425, E-mail: rosnthl@itsa.ucsf.edu.

\section{REFERENCES}

1. Greenwood BM, Mutabingwa T, 2002. Malaria in 2002. Nature 415: $670-672$.
2. Carter R, Mendis K, Roberts D, 2000. Spatial targeting of interventions against malaria. Bull World Health Organ 78: 14011411.

3. Robert V, Macintyre K, Keating J, Trape JF, Duchemin JB, Warren M, Beier JC, 2003. Malaria transmission in urban subSaharan Africa. Am J Trop Med Hyg 68: 169-176.

4. Trape JF, Lefebvre-Zante E, Legros D, Ndiaye G, Bouganali H, Druilhe P, Salem G, 1992. Vector density gradients and the epidemiology of urban malaria in Dakar, Senegal. Am J Trop Med Hyg 47: 181-189.

5. Thompson R, Begtrup K, Cuamba N, Dgedge M, Mendis C, Gamage-Mendis A, Enosse S, Barreto J, Sinden R, Hogh B, 1997. The Matola Malaria Project: a temporal and spatial study of malaria transmission and disease in a suburban area of Maputo, Mozambique. Am J Trop Med Hyg 57: 550-559.

6. Trape JF, Lefebvre-Zante E, Legros F, Druilhe P, Rogier C, Bouganali H, Salem G, 1993. Malaria morbidity among children exposed to low seasonal transmission in Dakar, Senegal and its implications for malaria control in tropical Africa. Am J Trop Med Hyg 48: 748-756.

7. Thomas C, Lindsay S, 2000. Local-scale variation in malaria infection amongst rural Gambian children estimated by satellite remote sensing. Trans $R$ Soc Trop Med Hyg 94: 159-163.

8. Clarke S, Bogh C, Brown R, Walraven G, Thomas C, Lindsay S, 2002. Risk of malaria attacks in Gambian children is greater away from malaria vector breeding sites. Trans $R$ Soc Trop Med Hyg 96: 499-506.

9. Dorsey G, Njama D, Kamya MR, Cattamanchi A, Kyabayinze D, Staedke SG, Gasasira A, Rosenthal PJ, 2002. Sulfadoxine/ pyrimethamine alone or with amodiaquine or artesunate for treatment of uncomplicated malaria: a longitudinal randomised trial. Lancet 360: 2031-2038.

10. Njama D, Dorsey G, Guwatudde D, Kigonya K, Greenhouse B, Musisi S, Kamya MR, 2003. Urban malaria: primary caregivers' knowledge, attitudes and practices and predictors of disease in a cohort of children. Trop Med Int Health 8: 685-692.

11. Gilles HM, Warrell DA, 1993. Bruce-Chwatt's Essential Malariology. London: Arnold.

12. Shiff C, 2002. Integrated approach to malaria control. Clin Microbiol Rev 15: 278-293. 